\title{
Association between strength with day sleepiness in individuals with Parkinson's disease
}

\section{Associação entre força e sonolência diurna em pessoas com a doença de Parkinson}

\author{
Sacha Clael ${ }^{1,2}$ \\ (D) https://orcid.org/0000-0002-6159-3490 \\ Camila Wells ${ }^{1}$ \\ (D) https://orcid.org/0000-0002-2537-8558 \\ Raphael Olegário \\ (D) https://orcid.org/0000-0001-8931-9533 \\ Sandro Nobre Chaves ${ }^{1,3}$ \\ (D) https://orcid.org/0000-0003-4936-1109 \\ Elaine Brandão \\ (D) https://orcid.org/0000-0003-0765-945X \\ Liana Caland ${ }^{1}$ \\ (D) https://orcid.org/0000-0001-7752-9357 \\ Márcio Mota Rabelo 4 \\ (1) https://orcid.org/0000-0003-0881-305X \\ Lídia Bezerra \\ (D) https://orcid.org/0000-0003-0661-6298
}

Abstract - The aim of this study is to analyze if there is an association between excessive daytime sleepiness with muscle strength in people with Parkinson's disease. This study is a cross-sectional study, with a quantitative approach. A total of 29 individuals with Parkinson's disease were recruited and classified in one of four stages of the modified Hoehn and Yahr scale. To assess the excessive daytime sleepiness the Epworth Sleepiness scale was used. The muscle strength was assess with handgrip and isokinetic dynamometers. There are non-significant correlation between Epworth Sleepiness scale with muscle strength, $\mathrm{p}<0.05$ and rho $<0.3$. The muscle strength assessed by handgrip and isokinetic dynamometers does not associated with excessive daytime sleepiness assessed by Epworth Sleepiness scale.

Key words: Hand strength; Muscle strength dynamometer; Signs and symptoms; Sleepiness.

Resumo - O objetivo do presente estudo é verificar se existe associação entre a sonolência diurna excessiva com a força muscular em pessoas com a doença de Parkinson. Este é um estudo transversal, com abordagem quantitativa. Um total de 29 indivíduos com a doença de Parkinson foram recrutados e classificados em uma das quatro categorias da escala de Hoehn and Yahr modificada. Para avaliar a sonolência diurna excessiva a escala de sonolência de Epworth foi utilizada. A força muscular foi avaliada por meio dos dinamômetros de preensão palmar e isocinético. Não foram encontradas correlaçôes significativas entre a escala de sonolência de Epworth com a força muscular $p<0.05$ and rho < 0.3. A força muscular avaliada pelos dinamômetros de preensão palmar e isocinético não se associaram com a sonolência diurna excessiva avaliada pela escala de sonolência de Eprworth.

Palavras-chave: Dinamômetro de força muscular; Força da mão; Sinais e sintomas; Sonolência.
1 University of Brasília. Faculty of Physical Education. Brasília, DF. Brazil.

2 Mauá Institute of Research \& Education. Brasília, DF. Brazil.

3 Integrated Faculty IESGO. Formosa, GO. Brazil.

4 University Center of Brasília Brasília, DF. Brazil.

Received: 08 October 2019 Accepted: 08 January 2020

How to cite this article Clael S, Wells C, Olegário R, Chaves SN, Brandão E, Caland L, Rabelo MM, Bezerra L. Association between strength with day sleepiness in individuals with Parkinson's disease. Rev Bras Cineantropom Desempenho Hum 2020, 22:e67953. DOl: http://dx.doi.org/10.1590/19800037.2020v22e67953

Copyright: This work is licensed under a Creative Commons Attribution 4.0 International License. 


\section{INTRODUCTION}

The Parkinson's disease (PD) is characterized by some regions degeneration in central nervous system, and one of them controls sleep, consequently sleep disorders are very common, and approximately $50 \%$ of people with PD have excessive daytime sleepiness ${ }^{1}$. Excessive daytime sleepiness is a nonmotor symptom common in people with $\mathrm{PD}$, such disorder do the person unable to stay alert and awake for most part of the day ${ }^{2}$, hence can lead to an unintended sleep episodes, interfere on day-to-day activities and reduce independence ${ }^{3}$. Non-motor symptoms can be considered important factors for quality of life in people with PD, and in some cases more important than motor symptoms, moreover, they may be a predictor of motor symptoms ${ }^{4}$.

The PD is known for symptoms that cause significant changes on motor control, but non-motor symptoms can cause more disorders and complications, in addition non-motor symptoms may be the cause of the motor disorders onset. Moreover, sleep disturbances on PD have been studied, since it can be influenced by motor symptoms, such as tremor and / or bradykinesia and by antiparkinsonian medications ${ }^{3}$. Therefore, excessive daytime sleepiness is correlated with dopaminergic medication and disturbances in Rapid Eye Movement sleep phase ${ }^{1}$.

Sleep plays a critical role in brain function and systemic physiology, including metabolism and appetite regulation, the functioning of immune, hormonal and cardiovascular systems ${ }^{5}$. Moreover, sleep disturbance contributes to poor sleep quality for subjects with $\mathrm{PD}^{6}$, furthermore sleep loss causes sleepiness, impairs the arousal mechanism and reduces the energy supply needed to power arousal, perceptual processes, motivation and effort $^{7}$. There is a phenomenon called "sleep benefit" which patients with good nights of sleep have their motor functions improved and some can even wait a little longer to take the first medicine dose of day ${ }^{8}$.

Sleep is responsible for restoring the body, and one of its roles is to regulate the testosterone ${ }^{9}$. The testosterone decreases with age ${ }^{10}$ and follows a circadian rhythm in which during the day it decreases until arriving in small levels at the end of the day, and it increases during sleep, thus the sleep is one of the major determinants of testosterone production or secretion'.

It is known that there is a negative association between sleep disorders with muscle strength ${ }^{11}$, functionality ${ }^{12}$ and testosterone ${ }^{13}$ in healthy individuals. Also, the literature reported a low muscle strength associated with an increased falls risk ${ }^{14}$. Therefore, is necessary to know if there are such associations in people with PD, so the aim's study is to analyze if there is an association between excessive daytime sleepiness with muscle strength people with PD. We hypothesized that there is an negative association between excessive daytime sleepiness and muscle strength.

\section{METHOD}

\section{Participants}

A cross-sectional study, with a quantitative approach and convenience 
sampling technique. A total of 29 individuals, 22 men and 7 women, with PD were recruited and classified in one of four stages of the modified Hoehn and Yahr scale ${ }^{15}$. Individuals classified as 4 were excluded from the study. The subjects needed to visit the laboratory 2 times, with 48 hours of interval, first day for anthropometric, severity level, excessive daytime sleepiness and handgrip strength (HGS) measurements. The second day to assess the knee strength. Moreover, all the participants were evaluated in "on" medication period and instructed to not perform physical exercises on 24 hours prior to the tests. This study was approved by the Faculty of Health Sciences at University of Brasilia ethics committee under protocol number 1.510.490 and all volunteers signed the consent form .

\section{Excessive daytime sleepiness}

To assess excessive daytime sleepiness the Epworth Sleepiness scale was used ${ }^{16}$.

\section{Handgrip strength}

To assess HGS the JAMAR ${ }^{\circledR}$ hydraulic hand dynamometer (Patterson Medical, Warrenville, Illinois, USA) was used. The JAMAR ${ }^{\circledR}$ dynamometer is an isometric tool with 5 fixed grip positions and precision of $2 \mathrm{~kg}$. The American Society of Hand Therapists adapted protocol was used, flexed elbow at $90^{\circ}$, considering as a result the maximum values obtained in three trials performed in the evaluation in each hand. The volunteers chose which hand to begin the test and position of the fixed grip aiming for comfort ${ }^{17}$.

\section{Isokinetic Dynamometer}

To assess knee strength the Biodex system III Isokinetic Dynamometer (Biodex Medical, Inc., Shirley, NY) was used with the protocol adapted from Bottaro et al. ${ }^{18}$. To warm up and familiarization the voluntary performed 1 set of 10 repetitions of knee extension and flexion at $120 \%$ with 60 seconds of rest interval. Then, to assess the peak torque (PT) 3 sets of 5 repetitions of knee extension at $60 \%$ with 60 seconds of rest interval between sets were performed. The protocol was counterbalanced and performed in both legs.

\section{Statistical Analyses}

For sample characterization, descriptive statistics were performed with mean and standard deviation for quantitative variables and simple frequency for qualitative variables. To verify data normality the Shapiro-Wilk test was used. To correlate Epworth Sleepiness scale with HGS and PT, Spearman's test was performed. Statistical significance level was set at $p$ $\leq 0.05$ in all correlations. All analyses were performed using the SPSS 24 (IBM Corporation, Armonk, NY, USA, 24.0) for Windows.

\section{RESULTS}

The sample characterization are described in Table 1. 
Table 1. Sample characterization.

\begin{tabular}{lc}
\hline & Mean \pm SD \\
\hline Age (years) & $67.03 \pm 9.47$ \\
Epworth Sleepiness scale (score) & $9.45 \pm 0.83$ \\
HGS_R (kg.F) & $29.62 \pm 1.47$ \\
HGS_L(kg.F) & $27.03 \pm 1.46$ \\
PT_R (N.m) & $110.36 \pm 8.23$ \\
PT_L (N.m) & $113.23 \pm 7.66$ \\
Modified Hoehn and Yahr scale (f) & $f(\%)$ \\
Level - 1.0 & $4(13.8)$ \\
Level - 1.5 & $2(6.9)$ \\
Level - 2.0 & $16(55.2)$ \\
Level - 2.5 & $2(6.9)$ \\
Level - 3.0 & $5(17.2)$ \\
\hline
\end{tabular}

Note. SD = Standard Deviation; $f=$ absolute frequency; $\%=$ relative frequency; HGS = handgrip strength; $P T=$ peak torque; $R=$ right side; $L=$ left side; $N . m$ = Newtons meters; $k g . F=$ Kilograms force.

Table 2 shows that there was no association between Epworth Sleepiness scale with HGS and PT on both sides, right and left.

Table 2. Correlation between Epworth Sleepiness scale and strength variables.

\begin{tabular}{llllll}
\hline & & HGS_R & HGS_L & PT_R & PT_L \\
\cline { 2 - 6 } Epworth Sleepiness scale & rho & 0.204 & 0.108 & 0.145 & 0.095 \\
& $p$ & 0.28 & 0.57 & 0.45 & 0.62 \\
\hline
\end{tabular}

Note. $\mathrm{HGS}=$ handgrip strength; $\mathrm{PT}=$ peak torque; $\mathrm{R}=$ right side; $\mathrm{L}=$ left side; rho = correlation coefficient.

\section{DISCUSSION}

The results show that there was no significant association between sleep disturbance assessed by Epworth Sleepiness scale with muscle strength assessed by HGS and PT. A score limit for people with PD on the Epworth Sleepiness scale score is 8 , our sample was scored with 9, perhaps this can explained the non-association ${ }^{19}$, as well ass, people with PD are elderly, and the s the majority of older adults were not able to answer all of the Epworth Sleepiness scale items, because an increase in age lead a decrease in cognitive status ${ }^{20}$.

Excessive daytime sleepiness is associated with insonia ${ }^{21}$, in addition insomnia symptoms have been linked to reports of limitations in activities of daily living and related behaviors in three large community-based samples of older adults ${ }^{22}$. However, the present study results did not show association between sleep disturbance, excessive daytime sleepiness, with muscle strength, probably by sleep evaluation instrument chosen for the research ${ }^{6}$, or also because $\mathrm{PT}$ evaluation protocol used in another study was isometric ${ }^{13}$.

People with PD that have longer diagnostic time, higher severity level, higher functional disability, autonomic dysfunctions, excessive daytime 
sleepiness, higher motor complications and higher doses of antiparkinsonian drugs have more insomnia ${ }^{23}$. The rise of sleep disturbances during the aging process may reflect changes in circadian rhythms that occur in aging process, alongside with others health and lifestyle factors such as comorbidities increases ${ }^{24}$. Although, the study sample can be a limiting factor, because participants already practice some oriented physical activity, which minimizes sleep disorders ${ }^{10}$ and prevent the muscle strength ${ }^{5}$.

There is a relationship between poor sleep quality with lower muscle strength and lower testosterone levels in healthy aged. In this sense, changes in metabolism, hormones and immune system are observed in healthy elderlies with few sleep hours or with poor sleep quality ${ }^{13}$. Stress has been associated with the activation of the hypothalamic-pituitary-adrenal and the sympatho-adrenal-medullary axes, whereas corticotropin-releasing hormone, cortisol, and catecholamines are known to cause arousal and sleeplessness in humans and animals ${ }^{25}$. Our study did not find such a correlation in elderlies with $\mathrm{PD}$, we believe that it is by questionnaire type used to evaluate sleep.

The search for further clarifications about mechanisms that regulate maintenance of muscle mass and sleep, as well as relation between these two variables is important for the elderly with PD, since besides the sleep disorders ${ }^{26}$ these individuals present a statistically significant difference in skeletal muscle fibers morphometry when compared to neurologically healthy elderly, aged with PD have a smaller number of type IIb fibers and a larger number of type I fibers ${ }^{27}$.

Although motor units structure are integral in PD, their functionality is altered by an inability to maintain neural firing for a long time period, a smaller number of units recruited, a lower threshold and a smaller amplitude in action potential produced ${ }^{28}$. In view of these aspects, it is suggested that hormonal production related to muscle mass and strength maintenance may be associated with different mechanisms in PD.

Testosterone is highly associated with muscle mass and muscle strength, which is an essential determinant of physical function in old age, and older people who sleep between 6 to 10 hours/day without disturbance have highest testosterone levels 9 . People with PD have reduction in muscle strength and such factor can compromise their activities of daily living ${ }^{29}$. Therefore, the decrease in muscle strength may also be related to the sarcopenia process that is more pronounced in individuals with $\mathrm{PD}^{30}$.

It is suggested that symptoms such as muscle weakness and sleep disorders need to be evaluated with precise, objective and quantitative instruments in order to analyze which pathophysiological mechanisms explain relationship between them. Evaluation instrument type used, non-exclusion of non-elderly and physical activity non-control, are factors possibly interfered in present study.

Study limitations should be considered for future research. The small sample size which reduces the statistical power and the generalizability of our findings. Consideration should be given to the participants with some 
physical activity level and the fact that qualitative questionnaires are not most recommended to clarify correlational aspects between motor and non-motor deficits caused by PD. Therefore, others variables could interfere the results, such as cognition, depression, and other motor symptoms. For practical application, excessive daytime sleepiness maybe not affect muscle strength.

\section{CONCLUSION}

There is no association between excessive daytime sleepiness, assessed by Epworth Sleepiness scale, with muscle strength, evaluated by PT and HGS, in people with PD.

\section{COMPLIANCE WITH ETHICAL STANDARDS}

\section{Funding}

This research did not receive any specific grant from funding agencies in the public, commercial, or not-for-profit sectors. This study was funded by the authors.

\section{Ethical approval}

Ethical approval was obtained from the local Human Research Ethics Committee - University of Brasília and the protocol (no. 52721415.2.0000.0030) was written in accordance with the standards set by the Declaration of Helsinki.

\section{Conflict of interest statement}

The authors have no conflict of interests to declare.

\section{Author Contributions}

Conceived and designed the experiments: SC, CW, MMR, LB. Performed the experiments: SC, CW, EB, LC. Analyzed the data: SC, LB. Contributed reagents/materials/analysis tools: $\mathrm{SC}, \mathrm{SNC}, \mathrm{RO}, \mathrm{EB}$. Wrote the paper: SC, SNC, MMR, LB.

\section{REFERENCES}

1. W. P. Non-motor symptoms in Parkinson's disease. European Journal of Neurology 2008;15(s1):14-20.

2. Xiang Y-Q, Xu Q, Sun Q-Y, Wang Z-Q, Tian Y, Fang L, et al. Clinical Features and Correlates of Excessive Daytime Sleepiness in Parkinson's Disease. Front Neurol 2019;10:121.

3. H. AC. Nonmotor complications in Parkinson's disease. Mov Disord 2005;20(11):S23-S9.

4. Chaudhuri KR, Odin P. The challenge of non-motor symptoms in Parkinson's disease. In: Björklund A, Cenci MA, editors. Progress in Brain Research. 184: Elsevier; 2010. p. 325-41.

5. McArdle WD, Katch FI, Katch VL. Exercise physiology: nutrition, energy, and human performance: Lippincott Williams \& Wilkins; 2010. 
6. Silva-Batista C, de Brito LC, Corcos DM, Roschel H, de Mello MT, Piemonte MEP, et al. Resistance Training Improves Sleep Quality in Subjects With Moderate Parkinson's Disease. J Strength Cond Res 2017;31(8):2270-2277.

7. Xie L, Kang H, Xu Q, Chen MJ, Liao Y, Thiyagarajan M, et al. Sleep Drives Metabolite Clearance from the Adult Brain. Science 2013;342(6156):373-7.

8. van Gilst MM, van Mierlo P, Bloem BR, Overeem S. Quantitative Motor Performance and Sleep Benefit in Parkinson Disease. Sleep 2015;38(10):1567-73.

9. Auyeung TW, Kwok T, Leung J, Lee JSW, Ohlsson C, Vandenput L, et al. Sleep duration and disturbances were associated with testosterone level, muscle mass, and muscle strength-a cross-sectional study in 1274 older men. J Am Med Dir Assoc 2015;16(7):630.e1-6.

10. Araujo AB, O'Donnell AB, Brambilla DJ, Simpson WB, Longcope C, Matsumoto $\mathrm{AM}$, et al. Prevalence and incidence of androgen deficiency in middle-aged and older men: estimates from the Massachusetts Male Aging Study. J Clin Endocrinol Metab 2004;89(12):5920-6..

11. Chen Y, Cui Y, Chen S, Wu Z. Relationship between sleep and muscle strength among Chinese university students: a cross-sectional study. J Musculoskelet Neuronal Interact 2017;17(4):327-33.

12. Dam TT, Ewing S, Ancoli-Israel S, Ensrud K, Redline S, Stone K; , et al. Association between sleep and physical function in older men: the osteoporotic fractures in men sleep study. J Am Geriatr Soc 2008;56(9):1665-73.

13. Buchmann N, Spira D, Norman K, Demuth I, Eckardt R, Steinhagen-Thiessen E. Sleep, muscle mass and muscle function in older people: a cross-sectional analysis based on data from the Berlin Aging Study II (BASE-II). Dtsch Arztebl Int 2016;113(15):253-60.

14. Rosario JT, Martins NSdF, Peixinho CC, Oliveira LF. Effects of functional training and calf stretching on risk of falls in older people: a pilot study. J Aging Phys Act 2017;25(2):228-233.

15. Goetz CG, Poewe W, Rascol O, Sampaio C, Stebbins GT, Counsell C, et al. Movement disorder society task force report on the hoehn and yahr staging scale: status and recommendations the movement disorder society task force on rating scales for Parkinson's disease. Mov Disord 2004;19(9):1020-8.

16. Johns MW. Reliability and factor analysis of the Epworth Sleepiness Scale. Sleep 1992;15(4):376-81.

17. American Society of Hand T. Clinical assessment recommendations. Chicago (401 N. Michigan Ave., Chicago IL 60611-4267): The Society; 1992.

18. Bottaro M, Russo AF, Oliveira RJ. The Effects of Rest Interval on Quadriceps Torque During an Isokinetic Testing Protocol in Elderly. J Sports Sci Med 2005;4(3):285-90.

19. Kumar S, Bhatia M, Behari M. Excessive daytime sleepiness in Parkinson's disease as assessed by Epworth Sleepiness Scale (ESS). Sleep Med 2003;4(4):339-42.

20. Onen F, Moreau T, Gooneratne NS, Petit C, Falissard B, Onen SH. Limits of the Epworth Sleepiness Scale in older adults. Sleep Breath 2013;17(1):343-50.

21. Wilsmore BR, Grunstein RR, Fransen M, Woodward M, Norton R, Ameratunga S. Sleep habits, insomnia, and daytime sleepiness in a large and healthy communitybased sample of New Zealanders. J Clin Sleep Med 2013;9(6):559-66.

22. Foley DJ, Monjan AA, Brown SL, Simonsick EM, Wallace RB, Blazer DG. Sleep complaints among elderly persons: an epidemiologic study of three communities. Sleep 1995;18(6):425-32.

23. Zhu K, van Hilten JJ, Marinus J. The course of insomnia in Parkinson's disease. Parkinsonism Relat Disord 2016;33:51-57.

24. Neikrug AB, Ancoli-Israel S. Sleep disorders in the older adult-a mini-review. Gerontology 2010;56(2):181-9.

25. Monroe LJ. Psychological and physiological differences between good and poor sleepers. J Abnorm Psychol 1967;72(3):255-64. 
26. Factor SA, McAlarney T, Sanchez-Ramos JR, Weiner WJ. Sleep disorders and sleep effect in Parkinson's disease. Mov Disord 1990;5(4):280-5.

27. Kelly NA, Ford MP, Standaert DG, Watts RL, Bickel CS, Moellering DR, et al. Novel, high-intensity exercise prescription improves muscle mass, mitochondrial function, and physical capacity in individuals with Parkinson's disease. J Appl Physiol 2014;116(5):582-92.

28. Barghi E, Gladden M. Motor Unit Number Estimation in Normal and Parkinsonism Model of Medial Gastrocnemius Muscle in Rats. Int J Mol Cell Med 2013;2(2):72-9.

29. Corcos DM, Chen CM, Quinn NP, McAuley J, Rothwell JC. Strength in Parkinson's disease: Relationshp to rate of force generation and clinical status. Ann Neurol 1996;39(1):79-88.

30. Drey M, Hasmann SE, Krenovsky J-P, Hobert MA, Straub S, Elshehabi M, et al. Associations between Early Markers of Parkinson's Disease and Sarcopenia. Front Aging Neurosci 2017;9:53.

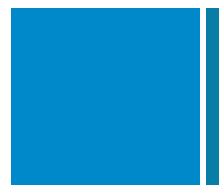

Corresponding author

Sandro Nobre Chaves

University of Brasilia, University Campus Darcy Ribeiro. Brasilia, DF, Brazil.

CEP: 70904-970

Email: sandronobrec@gmail.com 